\title{
Dual antiplatelet therapy up to the time of non-elective coronary artery bypass grafting with prophylactic platelet transfusion: is it safe?
}

Fida Charif ${ }^{1}$, Righab Hamdan²*, Genane Youness ${ }^{3}$, Ali El Zein ${ }^{4}$, Mohamad Issa ${ }^{4}$, Yehya Jassar ${ }^{5}$, Mahmoud Younes ${ }^{6}$ and Mohamad Saab ${ }^{5}$

\begin{abstract}
Background: Guidelines suggest that patients discontinue Clopidogrel at least 5 days prior to coronary artery bypass grafting (CABG). Those with acute coronary syndrome (ACS) are at high risk for myocardial infarction (MI) if not treated with dual antiplatelet therapy (DAPT). We sought to assess pre and post-operative outcomes of patients maintained on Clopidogrel and aspirin up to the time of surgery and compare them with those on aspirin alone.

Methods: From the cardiac surgery database, 240 patients were retrospectively registered between January and May 2017. There were 126 patients with ACS who underwent CABG on DAPT (Clopidogrel group [CG]) and 114 patients who underwent elective CABG on aspirin alone (control). The CG received intraoperative prophylactic platelet transfusion (PPT). Demographics, comorbidities, and laboratory data were prospectively entered at the time of surgery and were subsequently retrieved for analysis. Per and postoperative findings were identified and compared between both groups.

Results: The cohort consisted of 240 patients (mean age 61 years, $81.3 \%$ were male, SD \pm 9.58 ). Patients in the CG were younger (Median 57 vs. 63, $P$-value 0.001 ), and with male predominance ( $86 \%$ versus $75 \%, P$-value 0.028$)$. In addition, they had less prevalence for diabetes and renal failure as compared to control ( $P$-values 0.003, and 0.005, respectively). There were no significant differences between both groups in number of vessels grafts, duration of on-pump and aortic clamp. Hematologic laboratory data had also similar baseline values. The CG had similar bleeding rate, redo surgery and in-hospital death ( $P$-values non-significant), however more infection and total hospital stay as compared to control ( $p$-values 0.048 and 0.001 ).
\end{abstract}

Conclusion: Patients who are at increased risk for MI can be maintained on DAPT up to the time of CABG because surgery is safe when patients are offered PPT.

Keywords: Aspirine, Clopidogrel, CABG, ACS, Platelet transfusion

\footnotetext{
* Correspondence: mdrighabh@hotmail.com

${ }^{2}$ Division of Cardiology Medicine, Beirut Cardiac Institute, Beirut, Lebanon

Full list of author information is available at the end of the article
}

(c) The Author(s). 2019 Open Access This article is distributed under the terms of the Creative Commons Attribution 4.0 International License (http://creativecommons.org/licenses/by/4.0/), which permits unrestricted use, distribution, and reproduction in any medium, provided you give appropriate credit to the original author(s) and the source, provide a link to the Creative Commons license, and indicate if changes were made. The Creative Commons Public Domain Dedication waiver (http://creativecommons.org/publicdomain/zero/1.0/) applies to the data made available in this article, unless otherwise stated. 


\section{Introduction}

Many patients with acute coronary syndrome (ACS) and severe multi-vessel disease are offered non-elective coronary artery bypass grafting (CABG) within a short period of time since their last episode of chest pain [1]. The use of adenosine diphosphate antagonists in the preoperative period carries both benefits and risks. Clopidogrel has been frequently used in the management of ACS. It decreases the risk of new ischemic events in high-risk patients awaiting surgery, but on the other hand, it might increase the risk for post-operative bleeding [2, 3]. The American Heart Association/American College of Cardiology Foundation and the Society of Thoracic Surgeons recommend against continuation, and advise to stop Clopidogrel 5 to 7 days prior to surgery $[4,5]$. In addition, they advise for platelet transfusion in high-risk patients for bleeding prevention. However, there have been conflicting recommendations for platelet transfusion at the time of surgery. According to The British Society of Hematology (BSH) [6], the role of prophylactic platelet transfusion to reverse the effect of antiplatelet therapy is unclear. Our retrospective study aims at assessing the effect of exposure to Clopidogrel and aspirin within 5 days of surgery on post-operative bleeding, reoperation, in-hospital length of stay, mortality, and transfusion requirements, and compare the outcomes with patients who underwent CABG on aspirin alone.

\section{Methods}

This is a retrospective analysis, representing the routine practice in our center. From the cardiac surgical unit database at Beirut Cardiac Institute, a total of 240 consecutive patients were retrospectively identified between January 2017 and May 2017. Of them, 126 patients with ACS who underwent urgent or emergent isolated CABG and received Clopidogrel (within 5 days of surgery) and aspirin up to the day of the surgery, were assigned to a Clopidogrel group (CG), and compared to 114 patients who underwent elective CABG on aspirin alone up to the day of surgery, as a control group.

All surgical procedures were performed via a median sternotomy approach using cardiopulmonary bypass and cardioplegic arrest with cristalloid solution and cold water placed in the pericardial cavity during the clamp time.

Harvest of both internal thoracic arteries was performed in a skeletonized fashion, saphenous vein grafts were added in most of the patients.

All patients received $300 \mathrm{IU} / \mathrm{Kg}$ of intravenous unfractionated heparin before pump initiation, and $1 \mathrm{~g}$ of intravenous tranexamic acid while on-pump, as per our protocol. Patients in the CG received prophylactic 1 pool of platelets concentrate (8 units) early after discontinuation of the pump while in the operating room. Both groups were operated by the same surgical team.

Red blood cells transfusion was based on the patient's clinical condition rather than on a fixed hemoglobin value. However we followed mainly these rules:

- Hemoglobin less than $8 \mathrm{mg} / \mathrm{dl}$ for stable asymptomatic patients, aged less than 65 years, with mixed venous oxygen saturation (SVO2) above 65\%.

- Hemoglobin between 8 and $10 \mathrm{mg} / \mathrm{dl}$ for symptomatic patients aged more than 65 years and who have an ejection fraction less than $50 \%$ and SVO2 less than $65 \%$.

Indication of Fresh Frozen Plasma (FFP) transfusion was and increased in perioperative blood loss with prolonged international normalized ratio (INR) more than 1.5 .

Indications for platelet transfusion was thrombocytopenia less than $50 \times 10^{9} / \mathrm{L}$ and/or chest tube drainage more than $300 \mathrm{cc} /$ hour.

Demographics, comorbidities, laboratory data and other confounding factors were prospectively entered at the time of surgery and were subsequently retrieved for analysis.

\section{End points}

There were 3 co-primary endpoints: major bleeding, reoperation rate for bleeding, in hospital mortality and blood products transfusion requirement. Secondary endpoints were: 1) length of stay in the intensive care unit (ICU) and total hospital stay; 2) in-hospital infection; 3) stroke.

\section{Outcome characteristics}

Major bleeding was defined as chest tube drainage > $1500 \mathrm{ml}$, intracranial bleeding, or cardiac tamponade. Post-operative bleeding was defined as the total amount of chest tube drainage till its removal. Severe postoperative bleeding was defined as post-operative chest tube drainage more than $300 \mathrm{ml} /$ hour for 3 consecutive hours. Transfusion requirements were identified as the total amount of all blood product transfusions including unit packed red blood cells (UPC), fresh frozen plasma (FFP) and platelets concentrates during intraoperative and postoperative periods till patient's discharge. Stroke was defined as any hemorrhagic or ischemic events.

\section{Statistical analysis}

Continuous variables were described using median. Categorical variables were described as percentages. The chi-square test was used for categorical variables. The Mann -Whitney $U$ test was used for non parametric 
continuous variables. $P$-value of $<0.05$ was considered statistically significant.

\section{Results \\ Baseline characteristics and preoperative hematologic variables}

The cohort consisted of 240 patients (mean age 61 years, $81.3 \%$ were male, $\mathrm{SD} \pm 9.58$ ). All the patients in the Clopidogrel group were in acute coronary syndrome, $70 \%$ of these patients had positive troponin and $60 \%$ had critical left main lesion, whereas only $15 \%$ of the control group had left main involvement, and none of the control patients had positive troponin. In addition patients assigned to the CG were younger (age 57 vs. $63, P$-value $0.001)$, and with male predominance $(86 \%$ vs. $75 \%, P$ value 0.028 . We found as well less diabetes, dyslipidemia, and renal failure in the CG compared to the control group ( $P$-values 0.003, 0.028, and 0.005, respectively). There were no significant differences between both groups in platelets count, hematocrit, international normalized ratio and activated prothrombin time levels and number of vessels grafts. All results are shown in Table 1 laboratory data on admission are shown in Table 2.

\section{Per- and post-operative variables stratified by CG vs. control group}

Patients who were assigned to the CG had similar bleeding rate, (Fig. 1) redo surgery and in-hospital death (non-significant $P$-values), moreover there was no statistical significance regarding the amount of blood products transfusion and ICU stay between both groups. However, patients in the CG had more platelets transfusion (that was mainly attributed to the received preoperative prophylactic pools of platelets as previously described $P$-value 0.001 ), infection, and total hospital stay as compared to those in the control group ( $P$-values 0.048 and 0.001 respectively).
Reoperation rate was negligible in the 2 groups as well $(P$-value $=1)$. All results are shown in Table 3 . Multiple linear regression analysis showed that the increased total hospital stay and infection rate seen in the Clopidogrel group was mainly attributed to platelets transfusion $\left(\mathrm{F}(5,235)=603.56, P\right.$-value $<0.0001$ with $\left.R^{2}=0.93\right)$.

\section{Discussion}

Our center performs around one thousands open heart surgeries per year and is one of the most active centers in the region. Our data shows that cardiovascular surgery with sustained Clopidogrel is feasible and the increasing experience of the cardiovascular team makes it safe. However, past research showed conflicting results. In a prospective observational study Ouattara et al. [7] compared the perioperative bleeding rate in patients who underwent first time CABG on aspirin alone with those on Aspirin and Clopidogrel 5 days prior to surgery while receiving prophylactic low dose Aprotinin (a fibrinolysis inhibitor). There were no differences in the perioperative bleeding rate or transfusions requirements between both groups. In another randomized double blind placebo-controlled study [8], 136 patients with STsegment elevation myocardial infarction (STEMI) requiring $C A B G$ during the same hospitalization were assigned to either CG or placebo at the time of fibrinolysis therapy. There was no significant difference in perioperative bleeding rate, with a reduction of 30 days incidence of adverse ischemic events among the CG. Indeed, in a large prospective randomized trial, Ebrahimi et al. [9] showed that administration of Clopidogrel in non STEMI requiring CABG was associated with fewer adverse ischemic events and non-significant increased post-operative bleeding compared to patients who did not receive Clopidogrel. However, a 5-day washout period prior to surgery was considered in all patients in the CG.

Table 1 Patients characteristics

\begin{tabular}{|c|c|c|c|c|c|}
\hline \multirow{2}{*}{$\begin{array}{l}\text { Variable } \\
\text { Patients characteristics }\end{array}$} & \multicolumn{2}{|c|}{ Control group $(n=114)$} & \multicolumn{2}{|c|}{ Clopidogrel group $(n=126)$} & \multirow{2}{*}{$P$-value } \\
\hline & & & & & \\
\hline Sex, male & 86 & $(75.4)$ & 114 & $(86.5)$ & $.028^{\mathrm{a}}$ \\
\hline Age & 63 & $(57-70)$ & 58 & $(52-65)$ & $.001^{\mathrm{b}}$ \\
\hline Body weight & 77.5 & $(68-84)$ & 79 & $(69-85)$ & $.874^{\mathrm{b}}$ \\
\hline Dyslipidemic & 45 & $(39.5)$ & 33 & $(26.6)$ & $.028^{\mathrm{a}}$ \\
\hline Smoker & 85 & $(74.6)$ & 86 & $(68.3)$ & $.281^{\mathrm{a}}$ \\
\hline Diabetic & 67 & $(58.8)$ & 50 & $(39.7)$ & $.003^{\mathrm{a}}$ \\
\hline Hypertensive & 73 & $(64.0)$ & 72 & $(57.6)$ & $.276^{\mathrm{a}}$ \\
\hline Renal dysfunction & 13 & $(11.4)$ & 3 & $(2.4)$ & $.005^{\mathrm{a}}$ \\
\hline Ejection Fraction & 59 & $(50-63)$ & 55.5 & $(45-63)$ & $.368^{\mathrm{b}}$ \\
\hline
\end{tabular}

${ }^{a} x^{2}$ test, $n(\%)$

${ }^{\mathrm{b}}$ Mann-Whitney independent samples, median + interquartile range 
Table 2 Laboratory Data on admission

\begin{tabular}{|c|c|c|c|c|c|}
\hline \multirow{2}{*}{$\frac{\text { Variable on admission }}{\text { Labs }}$} & \multicolumn{2}{|c|}{ Control group $(n=114)$} & \multicolumn{2}{|c|}{ Clopidogrel group $(n=126)$} & \multirow{2}{*}{$P$-value } \\
\hline & & & & & \\
\hline Number of vessels grafts & 3.21 & $(3-4)$ & 3 & $(3-3)$ & .061 \\
\hline Aortic Clamp (min) & 41.5 & $(35-50)$ & 42 & $(37-51)$ & .310 \\
\hline ECC time (min) & 73.5 & $(62-83)$ & 71 & $(62-83)$ & .643 \\
\hline PTT & 35 & $(34-36)$ & 37 & (34-39) & .000 \\
\hline INR & 1 & $(1-1)$ & 1 & $(1-1)$ & .292 \\
\hline Platelets & 251.5 & $(198-289)$ & 243 & $(203-288)$ & .390 \\
\hline Hemoglobin & 13.7 & $(12-15)$ & 14 & $(13-15)$ & .155 \\
\hline Hematocrit & 41 & $(37-44)$ & 41 & $(38-44)$ & .596 \\
\hline
\end{tabular}

ECC Extracorporeal circulation

PTT Partial thromboplastin time test

INR International Normalized Ratio

${ }^{a} X^{2}$ test, $n(\%)$

${ }^{\mathrm{b}}$ Mann-Whitney independent samples, median + interquartile range

On the other hand, a meta-analysis of 34 studies including 22,584 patients [10] showed increased mortality and post-operative bleeding among Clopidogrel-exposed patients who underwent CABG; nevertheless, authors recommended that high-risk ACS patients should proceed with CABG without delay for a Copidogrel-free period. Another meta-analysis [11] of 6,385 ACS patients who required CABG showed that exposure to Clopidogrel within 5 days prior to CABG was associated with increased major bleeding and reoperation, although it showed significantly lower incidence of mortality and ischemic adverse events. The authors suggested that ACS patients, who were subsequently referred for CABG, should wait for a minimum of 5 days washout period to prevent bleeding and reoperation. Another study conducted by Nurozler et al. [12] showed increased bleeding rate and re-exploration for bleeding in patients exposed to Clopidogrel within a week of CABG. The duration of mechanical ventilation and length of stay were also longer compared to control group among

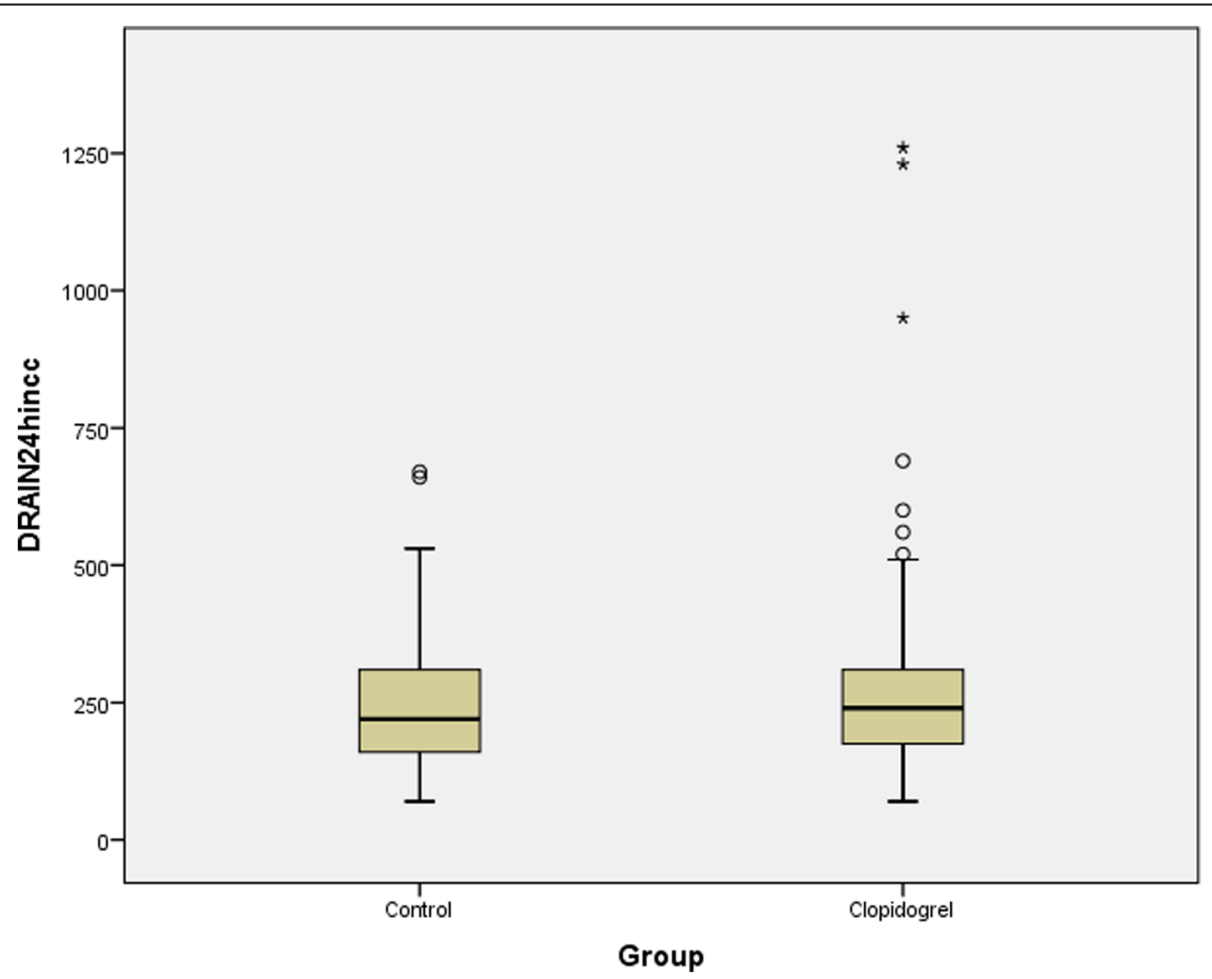

Fig. 1 Drain output per $24 \mathrm{~h}$ in $\mathrm{cc}$ 
Table 3 Results

\begin{tabular}{|c|c|c|c|c|c|}
\hline \multirow{2}{*}{$\frac{\text { Variable }}{\text { Results }}$} & \multicolumn{2}{|c|}{ Control group $(n=114)$} & \multicolumn{2}{|c|}{ Clopidogrel group $(n=126)$} & \multirow{2}{*}{$P$-value } \\
\hline & & & & & \\
\hline DRAIN/24 $\mathrm{h}$ in $\mathrm{cc}$ & 220 & $(160-313)$ & 240 & $(180-310)$ & $.476^{\mathrm{b}}$ \\
\hline Infection & 0 & $(0.0)$ & 3 & $(2.4)$ & $.048^{\mathrm{a}}$ \\
\hline Death & 2 & (1.8) & 1 & $(0.8)$ & $.501^{\mathrm{a}}$ \\
\hline Reoperation & 0 & $(0.0)$ & 1 & $(0.8)$ & $.256^{\mathrm{a}}$ \\
\hline Stroke & 0 & $(0.0)$ & 0 & $(0.0)$ & 1 \\
\hline \multicolumn{6}{|l|}{ Blood group } \\
\hline$A+$ & 47 & $(41.2)$ & 43 & $(34.1)$ & \multirow[t]{8}{*}{$.026^{\mathrm{a}}$} \\
\hline A- & 6 & $(5.3)$ & 8 & $(6.3)$ & \\
\hline $\mathrm{B}+$ & 14 & $(12.3)$ & 23 & $(18.3)$ & \\
\hline B- & 1 & $(0.9)$ & 6 & $(4.8)$ & \\
\hline$A B+$ & 9 & $(7.9)$ & 6 & $(4.8)$ & \\
\hline$A B-$ & 1 & $(0.9)$ & 1 & $(0.8)$ & \\
\hline $\mathrm{O}+$ & 27 & $(23.7)$ & 38 & $(30.2)$ & \\
\hline O- & 9 & $(7.9)$ & 1 & $(0.8)$ & \\
\hline Platelets per Op & 0 & $(0-0)$ & 8 & $(8-8)$ & $.001^{\mathrm{b}}$ \\
\hline UPC per OP & 0 & $(0-0)$ & 0 & $(0-0)$ & $.005^{\mathrm{b}}$ \\
\hline FFP per Op & 0 & $(0-0)$ & 0 & $(0-0)$ & $.087^{\mathrm{b}}$ \\
\hline UPC post Op & 0 & $(0-1)$ & 0 & $(0-0)$ & $.248^{b}$ \\
\hline FFP post Op & 0 & $(0-0)$ & 0 & $(0-0)$ & $.575^{b}$ \\
\hline UPC total & 0 & $(0-1)$ & 0 & $(0-0)$ & $.014^{\mathrm{b}}$ \\
\hline FFP total & 00 & $(0-0)$ & 0 & $(0-0)$ & $.470^{\mathrm{b}}$ \\
\hline Hemoglobin D1 post Op & 11.4 & $(10-12)$ & 11.4 & $(11-12)$ & $.755^{\mathrm{b}}$ \\
\hline Hemoglobin D4 post Op & 10.856 & $(10-12)$ & 10.5 & $(10-11)$ & $.367^{b}$ \\
\hline Hematocrit D0 post Op & 40.45 & $(37-43)$ & 41.00 & $(38-44)$ & $.041^{\mathrm{b}}$ \\
\hline Hematocrit D1 post Op & 33.4 & (3 1-37) & 34.05 & $(32-37)$ & $.980^{\mathrm{b}}$ \\
\hline Hematocrit D4 post Op & 32.234 & $(30-34)$ & 31.4 & $(30-34)$ & $.410^{\mathrm{b}}$ \\
\hline Platelets D0 post Op & 234 & $(184-277)$ & 245.5 & $(203-296)$ & $.083^{\mathrm{b}}$ \\
\hline Platelets D4 post Op & 220 & $(180-257)$ & 254 & $(210-321)$ & $.001^{\mathrm{b}}$ \\
\hline Length ICU/CSU stay(d) & 1.00 & $(1-1)$ & 1 & $(1-1)$ & $.098^{\mathrm{b}}$ \\
\hline Total hospital stay(d) & 5 & $(5-6)$ & 6 & $(6-7)$ & $.001^{\mathrm{b}}$ \\
\hline Creatinine baseline & 0.915 & $(1-1)$ & 0.87 & $(1-1)$ & $.106^{\mathrm{b}}$ \\
\hline Creatinine dc & 1.055 & $(1-1)$ & 1.055 & $(1-1)$ & $.791^{\mathrm{b}}$ \\
\hline
\end{tabular}

Op Operation

$D$ Day

UPC Unit packet cells

FFP Fresh frozen plasma

${ }^{a} x^{2}$ test, $n(\%)$

${ }^{\mathrm{b}}$ Mann-Whitney independent samples, median + interquartile range

those patients. Miceli et al. [13] showed that Clopidogrel within 5 days in combination with aspirin within 2 days of CABG was associated with an increased risk of postoperative myocardial infarction, bleeding and reoperation for bleeding. Likewise, other retrospective case control studies showed that patients who underwent CABG shortly after Clopidogrel exposure had increased risk of re-exploration for bleeding [14-16], and bleeding risk was significantly higher when Aspirin and Clopidogrel were continued up to 2 days prior to surgery [15].

Bleeding in cardiac surgery is whether surgically induced or due to acquired hemostatic defect. Platelet dysfunction due to antiplatelet therapy prior to CABG is the most important hemostatic factor that may lead to bleeding $[5,17]$. According to the American Heart Association/American College of Cardiology Foundation, 
ACS patients on dual antiplatelet therapy (DAPT) requiring non-elective CABG are considered to be at high risk for bleeding [18]. Recommendations provided by the American and European guidelines regarding prophylactic preprocedural platelet transfusion remain conflictual [19-21] and data regarding PPT in cardiac surgery on DAPT is still a matter of debate. In the absence of clear and questionable recommendations regarding this specific high-risk population, our results show the safety of operating on DAPT. Platelets transfusions should be viewed as scarce resource that has benefits and risks. Previously published data regarding this issue showed conflicting results. In an observational case control study [17], patients who proceeded with CABG (intervention group) and received isolated one pool of platelet transfusion early after discontinuation of the pump while in the operating room were compared to those who did not receive platelets. It showed no difference in reexploration, infection, organ failure and ischemic adverse events between groups. However, the intervention group had less chest tube drainage but experienced prolonged ICU stay, mechanical ventilation, need of inotropic medications and blood products transfusion requirement. In a retrospective cohort study, Karkouty et al. [22] showed that platelet transfusion in patients undergoing cardiac surgery was not associated with increased mortality and morbidity. In contrast, in a retrospective analysis of a double-blind placebo versus control study, Spiess et al. [23] showed that platelet transfusion in patients undergoing CABG was associated with increased serious adverse events, like infection, longer hospital stay, requirement of packed red blood cells transfusions, stroke and death compared to those who did not receive platelet transfusion.

Our study showed that prophylactic platelet transfusion in ACS patients requiring CABG while on DAPT up to less than 5 days prior to surgery is safe. There was no difference in the 3 co-primary and secondary endpoints between both groups. Moreover, chest tube drainage per $24 \mathrm{~h}$ in the CG and control group were similar (220 vs. $240 \mathrm{ml}, P$-value 0.476 ), and, compared to what was previously published, the amount was much smaller $[1-3,6-9,11-14]$. This finding was felt to be, though not truly confirmed, secondary to the surgical expertise and the protective effect of the peroperative prophylactic platelet transfusion.

\section{Strengths and limitations}

The timing of Clopidogrel discontinuation was precisely registered, and was less than 5 days prior to surgery, which might have prevented the adverse ischemic events. The amount of pre, intra, and post-operative blood product transfusions were analyzed. All patients were operated by the same surgical team and followed the same blood product transfusion protocol.

Despite those strengths, we recognize four limitations. First, this is a single center, retrospective, observational study. The sample size is relatively small given the short period of data collection. Second, no preoperative antiplatelet activity was done before PPT, because of non availability. Third, we did not compare the outcome to a true placebo group naïve to Clopidogrel and Aspirine, since in our routine practice we perform most of our surgeries without discontinuing Aspirine, nevertheless this might be an additive criterion for the feasibility and safety of open heart surgery without discontinuing any anti-platelet therapy. It would be of major interest to design a prospective study comparing ACS patients operated without delay and without discontinuing dual anti platelet therapy, while receiving platelet transfusion to ACS ptients operated with 5 to 7 days delay after discontinuing dual anti platelet therapy.

\section{Conclusions}

Based on our findings, we suggest that CABG on DAPT is most likely feasible and safe, especially when patients receive prophylactic peroperative platelet transfusion. More randomized controlled trials are needed to fully determine the role of prophylactic platelet transfusions, in urgent or emergent cardiac surgery, in preventing bleeding in patients on DAPT. Waiting for new results, we suggest that ACS patients requiring CABG proceed with surgery without delay for a Clopidogrel-free period.

\section{Abbreviations \\ ACS: Acute coronary syndrome; BSH: British Society of Hematology; CABG: Coronary artery bypass grafting; CG: Clopidogrel group; DAPT: Dual antiplatelet therapy; FFP: Fresh frozen plasma; ICU: Intensive care unit; MI: Myocardial infarction; PPT: Prophylactic platelet transfusion; STEMI: ST- segment elevation myocardial infarction; UPC: Unit packed red cells}

\section{Acknowledgments \\ We acknowledge the help of our secretary Mrs. Lina Hneineh and our perfusionist Mr. Ahmad Cham.}

\section{Authors' contributions}

All authors have read and approved the final manuscript, FC, MI and AZ collected data, FC had major contribution in writing the manuscript, $\mathrm{RH}$ participated to the literature review, data analysis and manuscript review and correction, GY performed the statistical analysis and reviewed the article, YJ, MY, and MS participated in data analysis and manuscript review.

Funding

None.

Availability of data and materials

Data and material are available upon request, and may be sent as supplementary material if required.

Ethics approval and consent to participate

The study was approved by the Rassoul Aazam University Hospital ethical committee. 


\section{Consent for publication}

There was no signed informed consent since no personal data were collected.

\section{Competing interests}

The authors declare that they have no competing interests.

\section{Author details}

${ }^{1}$ Division of Pulmonary Medicine, Beirut Cardiac Institute, Beirut, Lebanon. ${ }^{2}$ Division of Cardiology Medicine, Beirut Cardiac Institute, Beirut, Lebanon. ${ }^{3}$ Department of statistics, ISSAE, Cnam, Beirut, Lebanon. ${ }^{4}$ Department of Anesthesiology, Beirut Cardiac Institute, Beirut, Lebanon. ${ }^{5}$ Department of Cardiovascular surgery, Beirut Cardiac Institute, Beirut, Lebanon. ${ }^{6}$ Medical research center, Beirut Cardiac Institute, Rassoul Aazam Hospital, Beirut, Lebanon.

Received: 17 August 2019 Accepted: 18 November 2019

Published online: 27 November 2019

\section{References}

1. Head SJ, Davierwala PM, Serruys PW, Redwood SR, Colombo A, Mack MJ, et al. Coronary artery bypass grafting vs. percutaneous coronary intervention for patients with three-vessel disease: final five-year follow-up of the SYNTAX trial. Eur Heart J. 2014;35:2821-30.

2. Berger JS, Frye CB, Harshaw Q, Edwards FH, Steinhubl SR, Becker RC. Impact of clopidogrel in patients with acute coronary syndromes requiring coronary artery bypass surgery: a multicenter analysis. J Am Coll Cardiol. 2008:52(21):1693-701.

3. Fox KA, Mehta SR, Peters R, Zhao F, Lakkis N, Gersh BJ, et al. Clopidogrel in Unstable angina to prevent Recurrent ischemic Events Trial. Benefits and risks of the combination of clopidogrel and aspirin in patients undergoing surgical revascularization for non-ST-elevation acute coronary syndrome: the Clopidogrel in unstable angina to prevent recurrent ischemic events (CURE) Trial. Circulation. 2004;110(10):1202-8.

4. Ferraris VA, Ferraris SP, Saha SP, et al. Perioperative blood transfusion and blood conservation in cardiac surgery: the Society of Thoracic Surgeons and The Society of Cardiovascular Anesthesiologists clinical practice guideline. Ann Thorac Surg. 2007;83:27-86.

5. Fitchett D, Eikelboom J, Fremes $S$, et al. Dual antiplatelet therapy in patients requiring urgent coronary artery bypass grafting surgery: a position statement of the Canadian Cardiovascular Society. Can J Cardiol. 2009;25: 683-9.

6. Estcout LJ, Birchall J, Allard S, Hersey P, Kerr JP, et al. Guidelines for use of platelets: British society of hematology. Brit J Hem. 2017;177(1):157.

7. Ouattara A, Bouzguenda H, Le Manach Y, Léger P, Mercadier A, Leprince $P$, et al. Impact of aspirin with or without clopidogrel on postoperative bleeding and blood transfusion in coronary surgical patients treated prophylactically with a low-dose of aprotinin. Eur Heart J. 2007;28(8): 1025-32.

8. McLean DS, Sabatine MS, Guo W, et al. Benefits and risk of clopidogrel pretreatment before coronary artery bypass grafting in patients with ST elevation myocardial infarction treated with fibrinolytics in CLARITY- TIMI28. J Thromb Thrombolysis. 2007;24(2):85-91.

9. Ebrahimi R, Dyke C, Mehran R, et al. Outcomes following pre-operative clopidogrel administration in patients with acute coronary syndromes undergoing coronary artery bypass surgery: the ACUITY (Acute Catheterization and Urgent Intervention Triage strategy) trial. J Am Coll Cardiol. 2009;53:1965-72.

10. Nijier SS, Watson G, Athanasiou T, Malik IS. Safety of clopidogrel being continued until the time of coronary artery bypasses grafting in patients with acute coronary syndrome: a meta-analysis of 34 studies. Eur Heart J. 2011;32(23):2970-88.

11. Cao C, Indraratna P, Ang SC, Manganas C, Park J, Bannon PG, et al. Should clopidogrel be discontinued before coronary artery bypass grafting for patients with acute coronary syndrome? A systematic review and metaanalysis. J Thorac Cardiovasc Surg. 2014;148(6):3092-8.

12. Nurozler F, Kutlu T, Küçük G, Okten C. Impact of clopidogrel on postoperative blood loss after non-elective coronary bypass surgery. Interact Cardiovasc Thorac Surg. 2005:4(6):546-9.

13. Miceli A, Duggan SM, Aresu G, de Siena PM, Romeo F, Glauber M, et al. Combined clopidogrel and aspirin treatment up to surgery increases the risk of postoperative myocardial infarction, blood loss and reoperation for bleeding in patients undergoing coronary artery bypass grafting. Eur J Cardiothorac Surg. 2013;43(4):722-8.

14. Alström U, Granath F, Friberg O, Ekbom A, Ståhle E. Risk factors for reexploration due to bleeding after coronary artery bypass grafting. Scand Cardiovasc J. 2012:46(1):39-44.

15. von Heymann C, Redlich U, Moritz M, Sander M, Vargas Hein O, Grubitzsch $\mathrm{H}$, et al. Aspirin and clopidogrel taken until 2 days prior to coronary artery bypass graft surgery is associated with increased postoperative drainage loss. Thorac Cardiovasc Surg. 2005;53(6):341-5.

16. Kremke M, Tang M, Bak M, Kristensen KL, Hindsholm K, Andreasen JJ, et al. Antiplatelet therapy at the time of coronary artery bypasses grafting: a multicentre cohort study. Eur J Cardiothorac Surg. 2013;44(2):e133-40.

17. van Hout FM, Hogervorst EK, Rosseel PM, et al. Does a platelet transfusion independently affect bleeding and adverse outcomes in cardiac surgery? Anesthesiology. 2017;126(3):441-9.

18. Ferraris VA, Ferraris SP, Saha SP, Hessel EA 2nd, et al. Perioperative blood transfusion and blood conservation in cardiac surgery: the society of thoracic surgeons and the society of cardiovascular anesthesiologists clinical practice guideline. Ann Thorac Surg. 2007;83(5, Supplement):S27-86.

19. Kumar A, Mhaskar R, Grossman BJ, et al. Platelet transfusion: a systematic review of the clinical evidence. Transfusion. 2015;55(5):1116-27.

20. Schmidt AE, Henrichs KF, Kirkley SA, Refaai MA, Blumberg N. Prophylactic preprocedure platelet transfusion is associated with increased risk of thrombosis and mortality. Am J Clin Pathol. 2017;149(1):87-94.

21. Vaglio S, Gentili S, Marano G, Pupella S, Rafanelli D, Biancofiore G, Antonioli $P$, Velati $C$, Liumbruno GM. The Italian regulatory guidelines for the implementation of patient blood management. Blood Transfus. 2017;15(4): 325-8.

22. Karkouti K, Wijeysundera DN, Yau TM, Callum JL, Meineri M, Wasowicz M, et al. Platelet transfusions are not associated with increased morbidity or mortality in cardiac surgery. Can J Anaesth. 2006;53:279-87.

23. Spiess $B D$, Royston $\mathrm{D}$, Levy JH, et al. Platelet transfusions during coronary artery bypass graft surgery is associated with serious adverse outcomes. Transfusion. 2004:44:1143-8.

\section{Publisher's Note}

Springer Nature remains neutral with regard to jurisdictional claims in published maps and institutional affiliations.

\section{Ready to submit your research? Choose BMC and benefit from:}

- fast, convenient online submission

- thorough peer review by experienced researchers in your field

- rapid publication on acceptance

- support for research data, including large and complex data types

- gold Open Access which fosters wider collaboration and increased citations

- maximum visibility for your research: over $100 \mathrm{M}$ website views per year

At $\mathrm{BMC}$, research is always in progress.

Learn more biomedcentral.com/submissions 